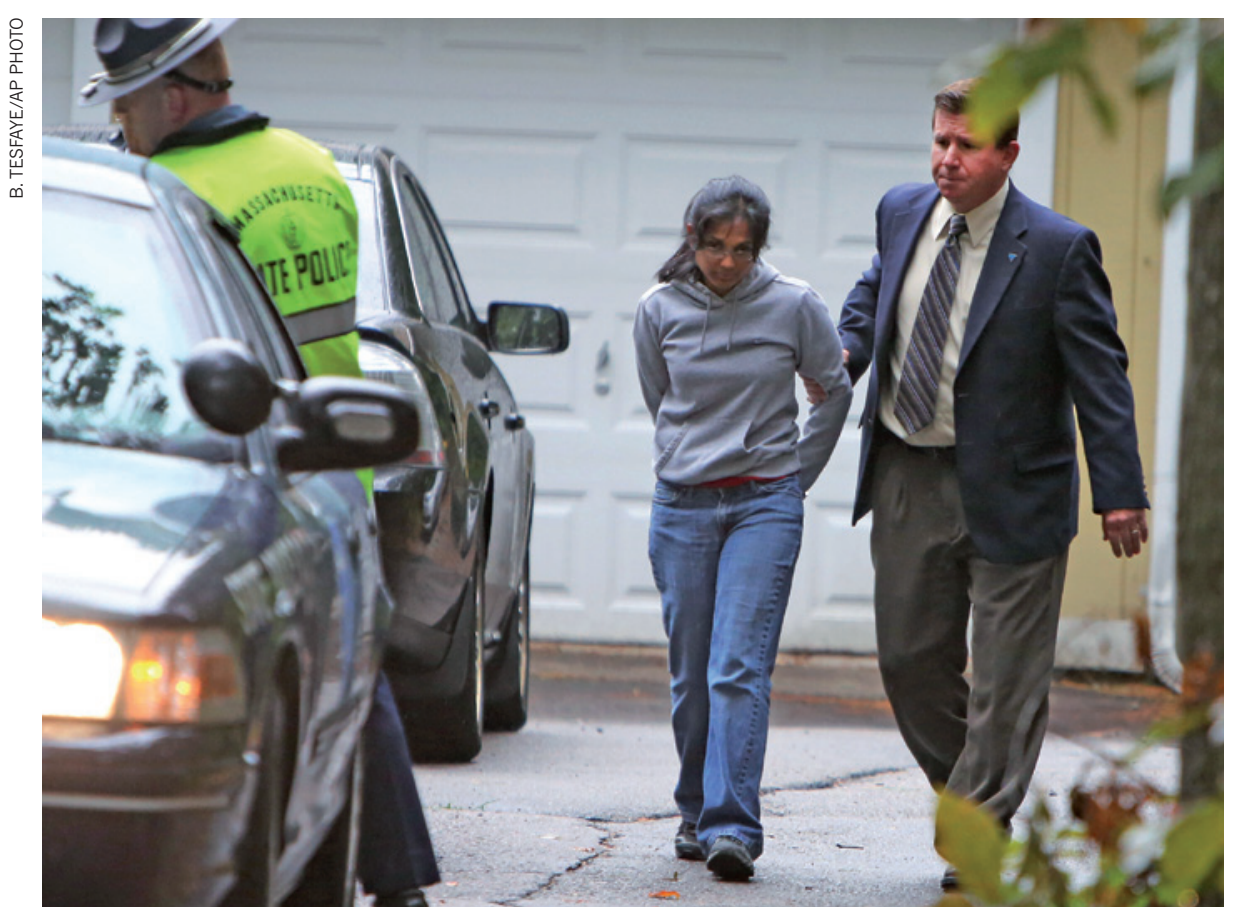

Annie Dookhan, a former forensic chemist in Massachusetts, has been charged with obstructing justice.

FORENSICS

\title{
Boston scandal \\ exposes backlog
}

\section{Chemist charged with fraud shows system under pressure.}

\section{BY EUGENIE SAMUEL REICH}

$\mathrm{T}$ he numbers are shocking: 1,100 people are in jail on the basis of evidence that may have been tampered with, and 34,000 criminal cases could be affected. The fallout stems from the work of just one forensic chemist, who is alleged to have faked test results on suspected drug samples.

The revelations and the subsequent arrest on 28 September of Annie Dookhan, who worked at a state-run laboratory in Boston, Massachusetts, have rattled the US forensics community and raised questions about oversight across the profession. Nature has learned that the facility had applied for federal funding to help to clear a backlog of some 8,000 cases - a full year's work. The situation parallels that of overburdened forensic labs across the United States.

"If you think this couldn't happen in your lab, you're naive," says Robin Cotton, director of the forensic-sciences programme at Boston University and a former forensic-lab director. "Lab directors all over the country are paying attention." Cotton and others say that the affair highlights a resourcing problem that is putting pressure on US forensic-lab workers and their supervisors, who need to bring cases to court fast, but without compromising the integrity of test results.

Dookhan has pleaded not guilty to charges of obstructing justice by falsifying data in two criminal cases, and of lying under oath about her qualifications. However, a wide-ranging confession by Dookhan documented in a

\section{SYSTEM OVERLOAD}

Demands on US forensic labs have expanded and so has the proportion of backlogged cases.

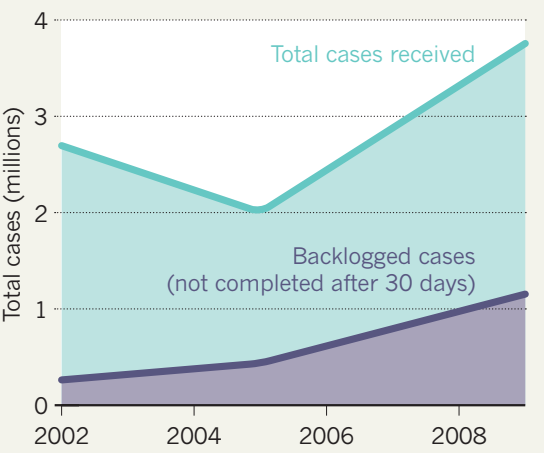

police report published by The Boston Globe implies that she falsified results on numerous occasions over the past 2-3 years. In most cases, she had guessed the nature of samples she had been asked to test; but "a few times" she had recorded the results of negative drug tests as being positive. Because Dookhan wasn't able to tell police which samples she had faked, and has said that she sometimes contaminated samples after the fact so that they would conform to her guesses, the possibility of wrongful conviction now swirls around the tens of thousands of cases on which she worked. Those who are currently serving jail terms are set to have their cases reviewed in court hearings that will begin on 15 October.

Dookhan's role at the lab was to identify compounds found by police that were suspected to be drugs. Police interviews with her former colleagues reveal that she tested more samples in less time than any other chemist in the lab - a record of productivity that raised eyebrows and had generated complaints from co-workers. In one instance, a top official reacted to concerns by giving Dookhan a special project to try to "slow her down".

Dookhan resigned in March while facing termination proceedings. The director of analytical chemistry has been fired, the lab bureau chief has resigned and Dookhan's direct supervisor faces disciplinary proceedings. Massachusetts public-health commissioner John Auerbach has also resigned, taking responsibility for the loss of confidence in the state's forensic work as a result of the scandal.

\section{RESOURCE PROBLEM}

Forensic labs in the United States are under a great deal of pressure to keep up with increasing case loads. In Massachusetts, for example, Nature has found that the National Institute of Justice (NIJ) in Washington DC allocated the state police at least US\$1.2 million from 2009 and 2011 to try to clear backlogs, in part by hiring an extra drug chemist and by buying new equipment. A spokeswoman for the NIJ has confirmed that some of the funding was routed to the lab in which Dookhan worked. The grants came with a requirement to provide oversight and report on any allegations or suspicions of wrongdoing that might affect the integrity of forensic science, but the NIJ says that nothing had been reported by state police by the end of 2011 .

Censuses of US forensic labs show that as many as one in four requests by law enforcement for forensic work are not acted on within 30 days. That has led to an ever-increasing backlog that accounts for a growing proportion of the workload (see 'System overload') The backlog is worst for DNA testing, which has become a major focus for groups interested in wrongful convictions. However, with drug law enforcement a priority in the US justice system, labs that test drugs are also being 
- swamped with cases.

Interviews documented in the police report suggest that a key cause of the backlogging at the lab is a 2009 US Supreme Court decision known as Melendez-Diaz v. Massachusetts, which overturned a drug conviction because the defence had been refused permission to cross-examine the forensic scientists who tested samples seized from a suspect. The result means that defence attorneys are now more likely to call forensic scientists into court to testify. "They're spending all their time in the courtroom and not the laboratory," says Ralph Keaton, executive director of the American Association of Crime Laboratory Directors Laboratory Accreditation Board in Garner, North Carolina. "Then the backlog grows."

A bill now before the US Congress aims to improve the quality of forensic science by providing funding for research and for development of national standards. But the bill does not include funding to clear backlogs. Stephen Saloom, policy director at the Innocence
Project in New York, which seeks to uncover wrongful convictions, says that even if the bill passes it won't provide an immediate remedy for cases of deliberate evidence tampering.

Dookhan's attorney, Nicolas Gordon, says that his client is not speaking to the media. Dookhan has been released on bail until a court hearing on 3 December. Gordon acknowledges allegations against his client but won't comment on their veracity. "It's a fluid situation that could change over the next few months," he notes. -

Use of population-genetic data to predict economic success sparks war of words.

\section{BY EWEN CALLAWAY}

\section{"T} he invalid assumption that correlation implies cause is probably among the two or three most serious and common errors of human reasoning." Evolutionary biologist Stephen Jay Gould was referring to purported links between genetics and an individual's intelligence when he made this familiar complaint in his 1981 book The Mismeasure of Man.
Fast-forward three decades, and leading geneticists and anthropologists are levelling a similar charge at economics researchers who claim that a country's genetic diversity can predict the success of its economy. To critics, the economists' paper seems to suggest that a country's poverty could be the result of its citizens' genetic make-up, and the paper is attracting charges of genetic determinism, and even racism. But the economists say that they have been misunderstood, and are merely using

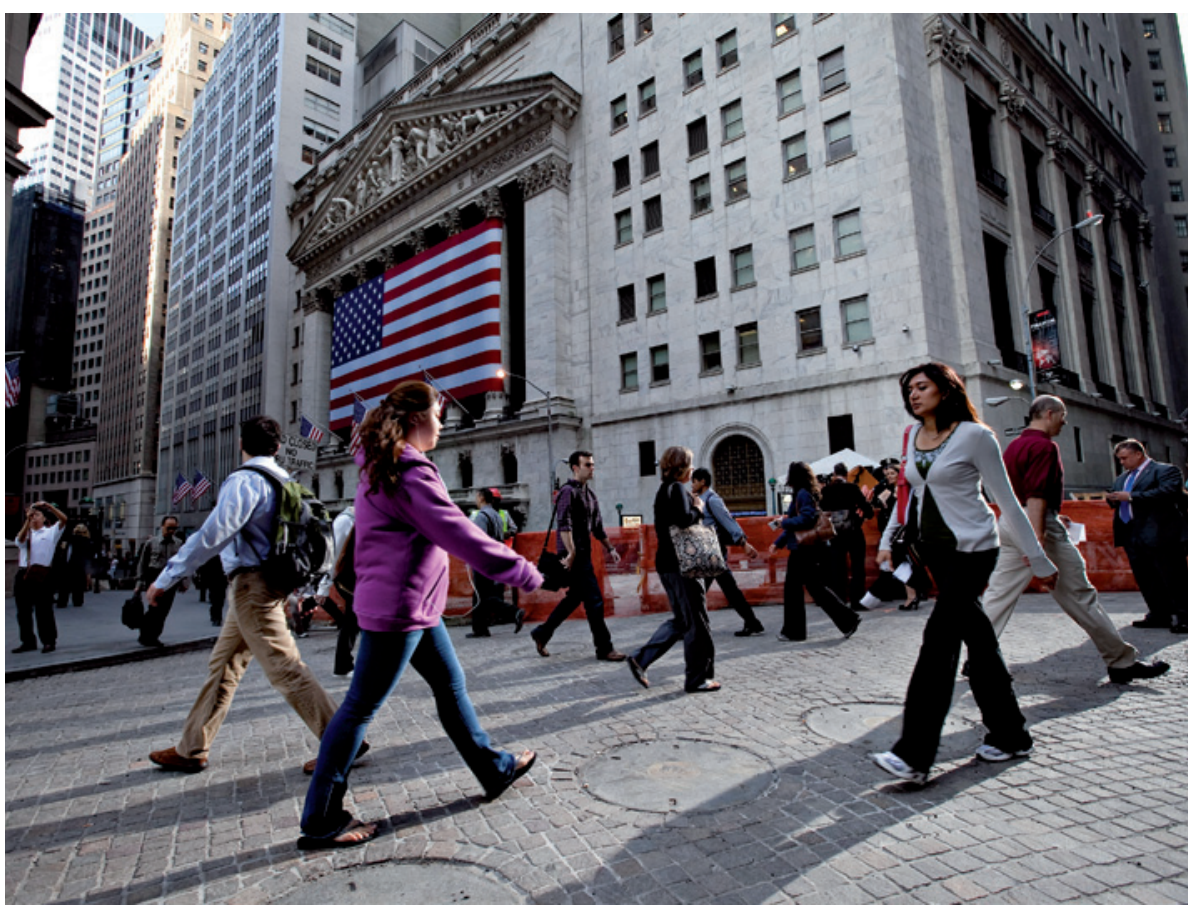

The United States has the right amount of genetic diversity to buoy its economy, claim economists. genetics as a proxy for other factors that can drive an economy, such as history and culture. The debate holds cautionary lessons for a nascent field that blends genetics with economics, sometimes called genoeconomics. The work could have real-world pay-offs, such as helping policy-makers "reduce barriers to the flows of ideas and innovations across populations", says Enrico Spolaore, an economist at Tufts University near Boston, Massachusetts, who has also used global genetic-diversity data in his research.

But the economists at the forefront of this field clearly need to be prepared for harsh scrutiny of their techniques and conclusions. At the centre of the storm is a 107-page paper by Oded Galor of Brown University in Provi dence, Rhode Island, and Quamrul Ashraf of Williams College in Williamstown, Massachusetts ${ }^{1}$. It has been peer-reviewed by economists and biologists, and will soon appear in American Economic Review, one of the most prestigious economics journals.

The paper argues that there are strong links between estimates of genetic diversity for 145 countries and per-capita incomes, even after accounting for myriad factors such as economic-based migration. High genetic diversity in a country's population is linked with greater innovation, the paper says, because diverse populations have a greater range of cognitive abilities and styles. By contrast, low genetic diversity tends to produce societies with greater interpersonal trust, because there are fewer differences between populations. Countries with intermediate levels of diversity, such as the United States, balance these factors and have the most productive economies as a result, the economists conclude. 